Zaur Gasimov und Carl Antonius Lemke Duque (Hg.), Oswald Spengler als europäisches Phänomen. Der Transfer der Kultur- und Geschichtsmorphologie im Europa der Zwischenkriegszeit 1919-1939, Vandenhoeck \& Ruprecht Verlag, Göttingen 2013, 327 S.

\title{
Marian Pătru*
}

Im Jahr 1919 beendete Oswald Spengler nach fünfähriger Arbeit sein wichtigstes Buch zur Philosophie der Geschichte, in dem er die Ursachen der Zivilisationskrise Europas seiner Zeit zu erklären versuchte. In der Zwischenkriegszeit wurde seine Diagnose aus „Der Untergang des Abendlandes“(1919) wie auch aus ,Jahre der Entscheidung“(1933) von den verschiedenen intellektuellen und politischen Kreisen aus ganz Europa rezipiert. Im vorliegenden Band geht es um die Verschiedenartigkeit der Rezeptionen Spenglers zwischen 1919 und 1939.

Der von Zaur Gasimov und Carl Antonius Lemke Duque veröffentlichte Band ist das Ergebnis einer internationalen und interdisziplinären Tagung, die im Juni 2012 am Leibniz-Institut für Europäische Geschichte in Mainz stattfand. Das Thema dieser Tagung war „Zwischen Verehrung und Verachtung - Der Transfer der Kulturmorphologie Oswald Spenglers im Europa der Zwischenkriegszeit (1919-1939)“. Die Einheit dieses Bandes liegt in einer methodologischen Konstante: die Autoren der zwölf Beiträge versuchen die Mentalität verschiedener europäischer Gesellschaften der Zwischenkriegszeit darzustellen, indem sie die Stellungnahmen der Eliten dieser Gesellschaften zu den Theorien Spenglers beleuchten.

Regine Hömig („Abwehr - Aneignung - Widerspruch: Diskursive Strategien der katholischen Spengler-Rezeption in Österreich“) stellt die vielfältige Rezeption Spenglers im katholischen Milieu Österreichs dar. Die Autorin unterstreicht das streng apologetische und konservative Gitter, durch welches die Perspektive Spenglers über die Rolle des Christentums innerhalb der europäischen Zivilisation eingeschätzt wurde. Spenglers Meinung nach sei das Christentum ein rein historisches Phänomen, das sich denselben „biologischen“ Gesetzen unterwirft, d. h. Erscheinung-Entwicklung-Auslöschung, wie die Religionen anderer vorchristlicher Zivilisationen. Diese pessimistische Perspektive wurde vielfach kritisiert: vom Versuch, die Unwissenschaftlichkeit

\footnotetext{
Marian Pătru, PhD Student at the Institute of Orthodox Theology, Ludwig Maximilian University of Munich. Address: Str. Mitropoliei 20, Sibiu, Romania; e-mail: marianpatru@ gmail.com.
} 
der Theorien Spenglers zu begründen (mit Bezug auf die schon in Deutschland existierende Kritik), bis zum konfessionellen Anspruch, dass der Katholizismus nicht ein dekadentes Phänomen der abendländischen Zivilisation sei, sondern die Chance der Wiederherstellung dieser Zivilisation, welche sich gerade durch die Revitalisierung des katholischen Denkens realisieren sollte (S. 24).

Zaur Gasimov analysiert die Rezeption Spenglers im bolschewistischen Russland. Die kommunistische intellektuelle Elite hat die Theorie des Untergangs des Abendlandes positiv rezipiert aber zugleich relativiert, indem sie in den Dienst der Bestätigung marxistischer Theorie über die Auslöschung der Bourgeoisie gestellt wird: Es heißt, das Abendland geht unter, aber nicht als Ganzes, sondern nur die herrschende Klasse (S. 78). Spengler wird also gleichzeitig akzeptiert und relativiert, um mit Hilfe seiner Theorien die marxistische Geschichtsphilosophie zu bestätigen. Auf der anderen Seite empfing die antikommunistische Intelligenz, z. B. N. Berdiaev, mit Begeisterung die pessimistische Betrachtung Spenglers, weil diese den eigenen Pessimismus gegenüber den politischen Veränderungen in Europa bestätigte - die nationalsozialistische Machtübernahme in Deutschland, die Stärkung der totalitären Macht in Russland (S. 75). Berdiaev stellt die Frage nach der Originalität Spenglers und betont, dass die Idee des Lebenszyklus der abendländischen Zivilisation und ihrer progressiven Degradierung schon im XIX. Jahrhundert von Konstantin Leontiev geäußert wurde (S. 73).

Dieselbe Idee des Fehlens von Originalität befindet sich im Zentrum der Kritik des italienischen Gelehrten Benedetto Croce. Michael Thöndl („Die Jahre der Entscheidung im faschistischen Imperium. Die Rezeption von Oswald Spengler in Mussolinis Italien“) zeigt, dass für Croce Spengler nichts weiter als ein Dilettant ist, der schon längst bekannte Ideen wiederholt: z. B. dass sich die Gesellschaft in Kreisläufen entwickele, eine Idee, die sich auch in den Schriften von Giambattista Vico im XVII. Jahrhundert befinde (S. 240). Die Annäherung zwischen Spengler und dem italienischen Faschismus wurde durch Mussolini selbst vermittelt, als Il Duce im Dezember 1933 das Buch „Jahre der Entscheidung" rezensierte. Die Art und Weise, in der Mussolini die Ideen Spenglers auswählt und sie interpretiert, offenbart deutlich seine politische Weltanschauung. Seiner Interpretation nach würde Spengler behaupten, dass Napoleon ein Italiener war und dass er die französische Hauptstadt zu seinem politischen Zentrum machte. Die Schlussfolgerung Mussolinis ist absehbar: unter seiner Herrschaft kann Italien die Erbin Frankreichs am Mittelmeer werden. Es ist offensichtlich, dass die kritischen Ideen Spenglers bezüglich des politischen Potenzials Italiens in der Weltpolitik unerwähnt bleiben (S. 250). 
Was in dieser historischen Skizze der Rezeption Spenglers in der Zwischenkriegszeit fehlt - eine Skizze, die z. B. die Beziehung zwischen der Philosophie Spenglers und dem Zionismus (S. 299) oder dem türkischen konservativen Milieu (S. 283) usw. umfasst - ist eine Analyse der Rezeption Spenglers im Rumänien derselben Zeitspanne. Meine Kritik hat eine objektive Begründung. Aus den vorher dargestellten Beiträgen ergibt sich, dass die Politik (Russland und Italien) und die Konfession (Österreich) zentrale Elemente der Rezeption Spenglers waren. Das politische und intellektuelle Milieu Rumäniens der Zwischenkriegszeit wurde von einem rechtsextremen Phänomen (sehr ähnlich wie der Nationalsozialismus und der Faschismus) geprägt, nämlich der Legionärsbewegung. ${ }^{1}$ Unter den wichtigsten orthodoxen Intellektuellen damals waren der Theologe Nichifor Crainic und der Philosoph Nae Ionescu, die gleichzeitig Ideologen der Legionärsbewegung waren. Also haben wir hier zwei Intellektuelle, gebunden an die orthodoxen und nationalistischen Werte (d. h. konfessioneller Konservatismus), zugleich Ideologen einer rechtsextreme Bewegung (rumänischer Faschismus) und gleichzeitig gute Kenner der Ideen Spenglers. ${ }^{2}$ Eine solche Mischung von Konfession, Politik und Geschichtsphilosophie ist einer ausführlichen Analyse im Kontext des „europäischen Phänomens" würdig, das durch Spenglers Werk entstand.

1 Der spengler'sche Unterschied zwischen ,Kultur' und ,Zivilisation ‘ wird von Vasile Marin - einem Gründer der Legionärsbewegung - in seinen politischen Artikeln viel benutzt. Für eine Analyse der legionären Rezeption Spenglers durch Marin siehe: Mircea Platon „, The Iron Guard and the "Modern State». Iron Guard Leaders Vasile Marin and «Moța and the New European Order»" in: Fascism - Journal of Comparative Fascist Studies, 1 (2012), S. 65-90.

2 Für die Rezeption Spenglers durch Crainics Theologie der Kultur siehe sein Buch „Nostalgia Paradisului“ (Sehnsucht nach dem Paradies), Iasi 1994 (die Originalausgabe ist im Jahr 1940 erschienen), besonders das Kapitel „Kultur und Zivilisation“. Nae Ionescu hat in seinen Vorlesungen an der Universität die Ideen Spenglers benutzt, aber ohne den Namen des deutschen Philosophen zu erwähnen. Über das Problem der Plagiate Ionescus (nicht nur von Spengler) siehe die ausführliche Analyse von Marta Petreu in „Filosofii paralele“ (Parallele Philosophien), Iași 2013. 